\title{
Restrictions on seismic impact of blast in the open-pit border zone at the open-pit and combined mining
}

\author{
Vyacheslav Kutuev ${ }^{1 *}$ and Sergey Zharikov ${ }^{1}$, \\ ${ }^{1}$ Institute of mining Ural Branch of RAS, 620075 Ekaterinburg, Russia.
}

\begin{abstract}
The combined mining under the condition of underground mining in the aquifer rock mass of the open-pit sides raises an acute issue of joint drill-and-blast works (D\&B). The construction of an underground mine begins normally with the approach of the open-pit mine depth to the final marks. In this situation, if there is a volume for the cutback, it is very small, and the blast works come close to the limit open-pit contour, behind which the protected rock mass is located and in the future the underground mining is supposed to be carried out. The main task in the drill-and-blast works under such conditions is to preserve the stability of this rock mass. The well-timed shielding of the blast and creating the fracture surfaces by the trim blasting reduce the negative impact of the blast on the open-pit side, but do not always prevent the propagation of stress waves caused by the seismic effect along the rock mass. Therefore, restriction of the seismic effect of blast in the border zone is as important for the stability of the rock mass as professional deviated contour holes. Key words: explosion, blast works, seismic effect of blast, open and combined mining, permissible displacement rate of rock mass, dynamic strength, seismic stability of mines, integrity of mines.
\end{abstract}

\section{Introduction}

While conducting mining operations in the quarry and underground mines in one vertical plane, the following conditions must be observed: the abandonment of the safety pillar, ensuring the stability of the rock mass and of the quarry sides; the implementation of development systems, excluding the displacement (destruction) of the rock mass of the safety pillar; the limitation of the power of mass explosions and their seismic impact on the pillars, ceilings and ledges of the sides.

In the case of combined field development, when underground workings are located in the quarry array, the front of mining operations in the quarry is located in the direction towards the front of the development of underground stopping works. At underground stopping works, the front develops in the direction from the massif to the quarry $[1,2]$.

\section{Theory and results}

Blasting operations in the quarry should be carried out in such a way, that the velocity of seismic vibrations of rocks in the area of underground mining does not exceed the maximum permissible values for stability. To determine the permissible value of the seismic velocity, it is necessary to establish the permissible dynamic stress in the array. The permissible dynamic limit of strength is in accordance with the condition of seismic stability of the working [3]:

$$
\left[\sigma_{s t}\right]+\left[\sigma_{d y n}\right] \leq \sigma_{d y n},
$$

\footnotetext{
Corresponding author: slavik1988@mail.ru
} 
where $\left[\sigma_{\mathrm{st}}\right]-$ static stress in the array surrounding the working; $\left[\sigma_{\mathrm{dyn}}\right]-$ dynamic stress in the array (near the working); $\sigma_{\text {dyn }}-$ allowable dynamic tensile strength near the working.

The values of tensile strength for the sample and the array are significantly different ( 5 10 or more times). It is possible to estimate reliably the value of the static ultimate strength of an array only experimentally, which is impossible at the initial stages of designing the project. In some cases, it is possible to approximate the calculation taking into account the average coefficient of structural weakening and on the basis of the passport of the rock mass strength. As a rough approximation for the permissible dynamic tensile strength of rocks $\sigma_{\text {dyn }}$ the static limit of rock strength on raising proposal $\sigma_{\mathrm{p}}$ increased by $10-30 \%$ [4] can be taken.

According to [3], the permissible velocity of the array displacement can be determined by the formula:

$$
v_{\partial}=\frac{2 \sigma_{d y n}}{\gamma C} 981 \cdot 10^{3}, \mathrm{~cm} / \mathrm{s},
$$

where $\sigma_{\text {dyn }}-$ permissible dynamic strength of rock mass, $\mathrm{kgf} / \mathrm{cm}^{2} ; \gamma$ - rock mass density, $\mathrm{t} / \mathrm{m}^{3} ; C$ - the speed of sound in the rock mass, $\mathrm{cm} / \mathrm{s}$.

Adhering to the values of the indicators according to the SI system, the expression (2) can be written in the following form:

$$
v_{\text {д }}=\frac{\sigma_{\text {dyn }}}{\gamma C} 2604,1, \mathrm{~m} / \mathrm{s},
$$

where $\sigma_{\text {dyn }}$ - permissible dynamic strength of rocks, MPa; $\gamma$-rock density, $\mathrm{t} / \mathrm{m}^{3} ; C$ - the speed of sound in the rock, $\mathrm{m} / \mathrm{s}$.

The speed of seismic oscillations depending on the mass of explosives in the stage and the distance from the explosion to the protected object can be determined according to [5]

$$
v=K(\sqrt[3]{Q} / R)^{m}, \mathrm{~cm} / \mathrm{s},
$$

where $Q$ - the mass of simultaneously exploding charges (the mass of explosives in the deceleration stage), $\mathrm{kg} ; R$ - distance to the object, $\mathrm{m} ; K$ - coefficient depending on the blasting conditions. The value of $K$ varies depending on the rocks at the explosion site and the rocks surrounding the working [5]. While blasting rocky massif with surrounding working of rocky rock mass, $K=200$. While blasting rocky massif with surrounding working of semirocky rock mass, $K=400$. While blasting semirocky massif with surrounding working of semirocky rock mass, $K=600 ; m$ - the attenuation index of seismic waves. For distances up to $1500 \mathrm{~m}$, the attenuation of seismic waves can be assumed to be 1.5 [5].

Then, the dependence (4) can be represented as

$$
v=K \sqrt{\frac{Q}{R^{3}}}, \mathrm{~cm} / \mathrm{s} .
$$

By setting the permissible speed of seismic oscillations for the protected area of rocks, it is possible to determine the distance at which the blasting will not lead to a loss of stability of the rock mass near the underground workings.

To determine the allowable distances from the contour of the quarry to the underground workings, by converting the formula (5), $R$ can be expressed, where $v_{д}$ is calculated by the formula (3) and we get an expression of the following form

$$
R=\sqrt[3]{\frac{Q K^{2}}{v_{\text {д }}{ }^{2}}}, \mathrm{~m} .
$$


In the process of projecting mass explosions at a certain section of the quarry, the mass of explosives in the deceleration stage should be calculated taking into account the properties of the rock mass and the characteristics of protected workings. The oscillation rate should be calculated according to the formulas (3) - (4), the coefficient $K$ and the damping index of seismic vibrations $m$ are determined by instrumental measurements. In their absence, we can use the average dependence

$$
v=225(\sqrt[3]{Q} / R)^{1,6}, \mathrm{~cm} / \mathrm{s}
$$

after the results generalization of researching parameters of seismic waves in rock massifs of fortress $f$ from 8 to 16 after Protodiakonov scale [4].

The safety of the already passed workings is achieved, if the actual shift velocity rate $v$ will not exceed the allowable value $v_{\text {д }}$ for the type of lining. The support itself significantly increases the seismic resistance of the working and can be reflected by the coefficient $K_{\text {cy }}$. The permissible vibration velocity for workings of various purposes is shown in the table.

Then

$$
v_{\text {д }}=v / K_{\text {cy }}, \mathrm{cm} / \mathrm{s} .
$$

The values of $K_{\text {cy }}$ for different types of support are in the following proposals:

$\begin{array}{lll}\text { Without support } & - & 1.0 \\ \text { Spray-concrete } & - & 1.2-1.6 \\ \text { Anchor or rod } & - & 1.6-2.0 \\ \text { Concrete } & - & 2.2 \\ \text { Metal arch } & - & 2.5-3.0\end{array}$

Table. The permissible vibration velocity for workings of various purposes [5]

\begin{tabular}{|l|c|c|}
\hline \multirow{2}{*}{ Working type } & \multicolumn{2}{|c|}{ Permissible oscillation speed, cm/s } \\
\cline { 2 - 3 } & Multiple blasts & Single blasts \\
\hline $\begin{array}{l}\text { Particularly responsible workings (service length of } \\
\text { more than 10 years): railway tunnels, shafts, capital } \\
\text { galleries }\end{array}$ & 6 & 12 \\
\hline $\begin{array}{l}\text { Responsible workings (service length up to 10 } \\
\text { years): unloading yards, main crosscuts, the main } \\
\text { drifts }\end{array}$ & 12 & 24 \\
\hline $\begin{array}{l}\text { Workings with a limited service length (up to 3 } \\
\text { years): pumping orts and drifts }\end{array}$ & 24 & 48 \\
\hline $\begin{array}{l}\text { Workings with service length up to 1 year: delivery } \\
\text { and drilling orts and drifts, rising, graduation box } \\
\text { holes }\end{array}$ & 48 & 96 \\
\hline
\end{tabular}

The seismic impact of a short-delay blast with sufficient delay intervals is equivalent to the action of an instantaneous explosion of one stage of a short-delay blast. In this case, the total mass of charges, the restriction is not imposed. In most cases, the explosion interval of 20 to $40 \mathrm{~ms}$ is sufficient.

\section{Summary}

On the basis of the seismic stability restriction, other parameters of massive blast works in the quarry is being determined. The value of underground technological explosion during the quarry work is limited by the parameters of blasting in the excavation of workings and practically should not exceed a few kilograms per stage of deceleration. As a result, these explosions do not have a seismic effect on the sloping structures of the quarry.

At present, blasting agents can provide independent operation of each explosive charge in the well, that means, using this approach, it is possible to optimize the parameters of drilling and blasting operations and achieve a significant reduction in the effect of seismic 
impact of the explosion on the protected area and quarry facilities with the joined conduct of blasting on the surface and in the underground workings within the framework of the combined development of the field.

The studies were carried out within the framework of the State task №075-00581-19-00, theme №0405-2019-0005 (2019 - 2021), as well as with additional attraction of contractual funds.

\section{References}

1. Federal regulations and rules in the field of industrial safety "Safety rules for blasting operations", (Ekaterinburg, 2018) 244 pp. [In Russian].

2. Federal regulations and rules in the field of industrial safety "Safety rules for mining and processing of solid minerals", (Ekaterinburg, 2018) 208 pp. [In Russian].

3. V. A. Shchelkanov, P. S. Mironov, Influence of mass explosions on the stability of underground workings in the combined development of iron ore deposits. Proceedings of Institute of Mining of MFM of USSR, 36, 91 (Sverdlovsk, 1972) [In Russian].

4. M. I. Kartuzov, N. V. Pazdnikov, Prediction of seismic safety of underground workings while blasting. Proceedings of Institute of Mining of MFM of USSR, 68 (Sverdlovsk, 1982)

5. M. I. Kartuzov, N. V. Pazdnikov et al. Methods of providing seismic technology of blasting, (Sverdlovsk, 1984) 12 pp. [In Russian]. 